\title{
Cont $-8206160--1$
}

CONF-8206160--1

DE83 007617

IMRURITY DIFFOSION IN TRANSTTIONMMETAL OXIDES*

\author{
N. L. PETFRSON \\ Materials Science Division
}

Argonne National Laboratory, Argonne, IL 60439

JUNE 1982

\section{DISCLAIMER}

This report was prepared as an account of work sponsored by an agency of the United States Government. Neither the United States Government nor any agency thereof, nor any of their employees, makes any warranty, express or implied, or assumes any legal liability or responsibility for the accuracy, completeness, or usefulness of any information, apparatus, product, or process disclosed, or represents that its use would not infringe privately owned rights. Reference herein to any specific commercial product, process, or service by trade name, trademark, manufacturer, or otherwise does not necessarily constitute or imply its endorsement, reconmendation, or favoring by the United States Government or any agency thereof. The views and opinions of aithors expressed berein do not necessarily state or reflect those of the United States Government or any agency thereof.

*Work supported by the U.S. Department of Energy.

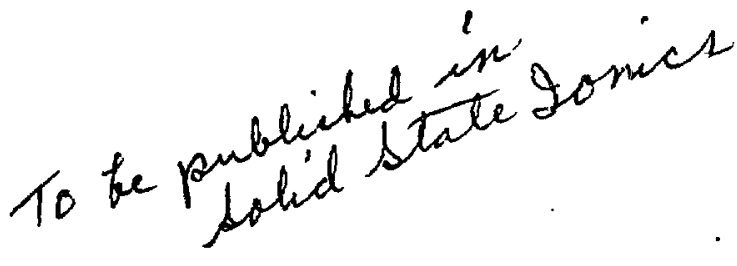


IMPURITY DIFFUSION IN TRANSITION METAL OXIDES*

\author{
N. L. PFTERSGN \\ Materials Science Division \\ Argonne Nationai Iaboratory, Argonne, II, 60439
}

\begin{abstract}
APSTRACT
Intrinsic tracer impurtty diffusion measurements in ceramic oxides have been primarfly confined to $\mathrm{Con}, \mathrm{Nin}$, and $\mathrm{Fe}_{3} \mathrm{O}_{4}$. Tracer impurity diffusion in these materials and $\mathrm{TiO}_{2}$, together with measurements of the effect of impurities on tracer diffusion ( $\mathrm{CO}_{\mathrm{O}}$ in $\mathrm{Nin}$ and $\mathrm{Cr}$ in $\mathrm{CoO}$ ), are revfewed and discussed in terms of impurity-defect interactions and mechanisms of diffusion. Divalent impurities in divalent solvents seem to have a weak interartion with vacancies bliereas trivalent inpurities in divalent solvents strongly influence the vacancy concentrations and significantiy reduce solvent jump frenuencies near a trivalent impurity. Impurities with sr.all lonic radil diffuse more slowly with a larger activation energy than impurities with larger lonic radil for all systems cunsidered in this review. Cobalt ions (a moderate size impurity) diffuse rapidly along the open channels parallel to the c-axis in $\mathrm{TiO}_{2}$ whereas chromium ions (a smaller-sized impurity) do not.
\end{abstract}




\title{
IMPURITY DIFEUSION IN TRANSITION METAL̈, OXIDES*
}

\author{
N. L. PETFRSON \\ Materlals Sclence Division \\ Argonne National Laboratory, Argonne, II, 60439
}

\section{Int roduction}

Impurity diffusion is the transport of any species other than the host material in the solid. Two tyjes of impurity diffusion coefficients are commonly used in the literature. The interdiffusion coefficient $D$ describes the process by which two adjacent solids of differing compositions homogenize by the mutual diffusion of species across a common boundary. This coefficient is composition dependent (hence, a function of position within the sample), and its interpretation in terms of defect properties is complicated by the presence of compositional gradients and net mass flow. The tracer diffusion coefficient $D^{*}$ refers to either selfor Impurity diffusion when the species of interest is at infinitely small concentration. The tracer diffusion coefficlent is independent of position In a homogeneous sample; even though there is a gradient of the radioactivity as a function of distance, a given atom "sees" only a homogeneous solid. Owing to the greater accuracy of measurement and ease of interpretation, only tracer diffusion experiments will be considered in this paper.

\footnotetext{
*Work supported by the U.S. Department of Energy.
} 
Two types of tracer-impurity diffusion measurements may be made that complement each other and help identify the details of the impurity diffusion process.

(a) The motion of an isolated impurity ion in an otherwise pure crystal may be measured. The availability of high specific activity (often carrier-free) tracers allow measurements to be made at indiffused-impurity .concentrations below the intrinsic defect concentration. Under these conditions the tracer atom follows a fump sequence as though no other 1. urity lons were in the crystal and at a defect concentre ion correspondinf to the pure crystal. The diffusion process is then relatively simple to treat theoretically. It is necessary only to specify the atomic jump frequencles and defect interaction energies for the few simple and well-defined solute-defect configurations. Impurity diffusion under these conditions in NiO, $\mathrm{Co}_{1-\delta^{O}} \mathrm{O}, \mathrm{Fe}_{3} \mathrm{O}_{4}$, and $\mathrm{THO}_{2}$ will be reviewed in sections 2 to 4.

(b) Self- and impurity tracer diffusion may be measured in crystals doped with controlied amounts of the impurity. The dopant will influence the concentratior of defects and jump frequencies of the ions throughout the crystal, but the concentration of an Indiffused tracer is sufficiently low that $D^{*}$ wlll he independent of position in the sample. If the concentration of randorly spaced impurity ions is sufficiently low so that the spheres of influence of different impurity atoms do not overlap (1-2\% dopant), the theory may be sufficiently simple to allow details of the impurity diffusion process to he deduced. The effect of Co additions to 
$\mathrm{N} 1 \mathrm{O}$ and $\mathrm{Cr}$ addition to $\mathrm{Co}_{1-\delta^{\circ}} \mathrm{O}$ on tracer diffusion will be discussed in section 5 .

2. Impurity Diffusion in $\mathrm{N} 10$ and $\mathrm{CO}_{1-\delta^{\circ}}$

Refore the results for impurity diffusion in $\mathrm{NiO}$ and $\mathrm{Co}_{1-\delta^{0}}$ are considered, the general formalism for impurity diffusion will be briefly riscussed.

\subsection{Impurity diffusion formalisa}

The temperature dependence of tie tracer self-diffusion coefficient is frequently found to ohey the Arrhenius equation

$$
D^{S}=D_{0}^{S} \exp \left(-0^{S} / k T\right)
$$

From simple reaction-rate theory, one may obtain the expressions

$$
n^{s}=h_{f}^{S}+h_{m}^{s}
$$

and

$$
D_{o}^{s}=a^{2} v^{s} f^{s} \exp \left[\left(s_{f}^{s}+s_{m}^{s}\right) / k\right]
$$

for diffusion hy a simple-defect mechanism in a cubic structure. The superscript $s$ refers to self-diffusion; $h_{f}$ and $h_{m}$ are the enthalples and $s_{f}$ and $s_{m}$ are the enthroples of defect formation and migration, respectively; a is the edge length of the elementary cube; $v$ is the vibration frequency of an atom about its equilibrium position in the jump direction; and $f$ is 
the correlation factor that accounts for the non-randomness of tracer atom jumps. For self-diffusion, $\mathrm{f}^{\mathrm{s}}$ is generally a temperature-independent constant that is determined by the diffusion mechanism and the crystal symmetry [1].

For impurity diffusion, the correlation factor $\mathrm{f}^{1}$ depends on the relative jump frequencies of the impurity and the neighboring solvent ions. The presence of the impurity will cliange the values of the jump , frequencies of the neifhboring solvent atoms rejative to the values in the ahsence of the impurity. Assuming that the effect of the in, urity is short-ranged, four different jump frenuencies for the vacancy near an 1mpurity lon may he defined for the fcc lattice. As shown in fig. $1, w_{1}$ is the frequency of exchange of a vacancy neighboring an impurity ion with any of the four solvent ions that are also neighbors of the impurity; $w_{2}$ is the frequency of exchange of the impurity and the vacancy; $w_{3}$ is the frequency of exchange of a vacancy neighboring an impurity with any of the seven solvent ions adjacent to the vacancy but not neighbors of the vacancy (dissociation jumps); $w_{4}$ is the frequency of the association jump (reverse of a $w_{3}$ jump); and all other jumps are assumed to take place with a frequency $w_{0}$, which is the frequency of the solvent-vacancy exchange in the pure solvent. The correlation factor for impurity diffusion $f^{1}$ in the fcc lattice may be expressed in terms of these various jump frequencies;

$$
f^{1}=\frac{w_{1}+7 / 2 F w_{3}}{w_{1}+w_{2}+7 / 2 F w_{3}},
$$


where $F$ is the fraction of vacancies making $w_{3}$ jumps that effectively do not return to the site from which the $w_{3}$ jump was made; $F$ is a known function of $w_{4} / w_{0}[2]$

If there is an impurity-vacancy interacticn. the energy to form a vacancy next to an impurity $h_{f}^{1}$ will be different from $h_{f}^{s}$. Similarly, the energy for an impurity-vacancy exchange $h_{m}^{i}$ may be different from $h_{m}^{s}$. The activation energy for Impurity diffusion $0^{i}$ will differ from $Q^{s}$ by an amount

$$
\begin{aligned}
\Delta 0 & =n^{i}-0^{s}=\left(h_{m}^{i}-h_{m}^{s}\right)+\left(h_{f}^{i}-h_{f}^{s}\right)-c \\
& =\Delta h_{m}+\Delta h_{f}-C,
\end{aligned}
$$

where $-\Delta h_{f}$ is the impurity-vacancy binding energy $h_{b}^{i-v}$ and $C$ is the temperature dependence of $\mathbf{f}^{\mathbf{i}}$;

$$
C=R \frac{\partial \ln f^{i}}{\partial(1 / T)}
$$

Each of the $w_{j}$ 's in eq. (4) may be written in the form of an Arrhenjus equation:

$$
w_{j}=v_{j} \exp \left(s_{m} / k\right) \exp \left(-h_{m, j} / k T\right)
$$

Since the various $h_{m, j}$ 's may be different, $f^{i}$ will vary with temperature. Values of $\Delta h_{m}, \Delta h_{f}$, and $c$ have been calculated fcr a large number of impuritles diffusing in $\mathrm{Cu}, \mathrm{Ag}, \mathrm{Al}$, and $\mathrm{Cd}$ [3]; good agreement between theory and experiment is found when a realistic interatoinic potential is avallable. Similar calculations have not been reported for metal oxides; 
however, the formalism above is valid for oxides and is useful for dis-cussing experimental results.

\subsection{Defert structure and mobility in $\mathrm{NiO}$ and $\mathrm{Co}_{1-\delta^{O}}$}

The oxides $\mathrm{N} 1 \mathrm{O}$ and $\mathrm{Co}_{1-\delta} \mathrm{O}\left(\mathrm{also} \mathrm{M}_{1-\delta}\right.$ and $\mathrm{Fe}_{1-\delta} \mathrm{O}$ ) have the $\mathrm{NaCl}$ structure and are metal-deficient at high temperatures [4]. The oxides can be descrihed by a general formula, $M_{1}-\delta^{0}$, in which the non-stoichiometric defect has been generally recognized as a cation vacancy. Electroneutrality in the crystal is preserved by the presence of an appropriate number of electron holes that compensate for missing cations. The value of $\delta$ is less than $10^{-3}$ for $\mathrm{N} 10$ and less than $10^{-2}$ for $\mathrm{Co}_{1-\delta} \mathrm{O}$. The defect structure and mohility is better known for $\mathrm{Co}_{1-\delta} \mathrm{O}$. The detalls of this defect structure that influence impurity diffusion are discussed in the following paragraphs for $\mathrm{Co}_{1-\delta^{O}}$.

The extensive measurements of the deviations from stolchiometry $\delta$ as a function of $\mathrm{PO}_{2}$ [5-10] show an excess of oxygen lons relative to cobalt Ions in $\mathrm{Co}_{1-\delta} \mathrm{O}$. The rapid cation tracer djffusion [5, 11-14] relative to anion tracer diffusion $[15]\left(\mathrm{D}_{\mathrm{Co}}^{\%_{\mathrm{K}}} / \mathrm{D}_{\mathrm{O}}^{*}-5 \times 10^{4}\right.$ at $\left.1200^{\circ} \mathrm{C}\right)$ strongly suggests that the excess oxygen ions are accommodated hy the formation of cation vacancies (and electron holes) rather than anion interstitials. Various charges are possible for the cation vacancies. The formation of neutral vacancies can he expressed as follows:

$$
1 / 2 o_{2}(g)=v_{C o}^{x}+o_{0}^{x}
$$


singly charged vacanctes can be formed hy the dissociation of neutral vacanctes :

$$
v^{x}=v_{C_{0}}^{\prime}+\dot{h}
$$

Further dissociation of elertron holes yields doubly charged vacancies:

$$
v_{\mathrm{Co}}^{\prime}=\mathrm{v}_{\mathrm{Co}}^{\prime \prime}+\dot{\mathrm{h}} \text {. }
$$

If only one type of cation vacancy is present, and the defect concentration is sufficiently small that defect-defect interactions can be neglected, then the application of the law of mass action to eqs. (8-10) allows one to relate the defect concentration to the oxygen partial pressure:

$$
\begin{aligned}
& {\left[\mathrm{v}_{\mathrm{Co}}^{\mathrm{x}}\right] \propto\left(\mathrm{p}_{\mathrm{O}_{2}}\right)^{1 / 2}} \\
& {\left[\mathrm{v}_{\mathrm{Co}}^{\prime}\right] \propto\left(\mathrm{p}_{\mathrm{O}_{2}}\right)^{1 / 4}} \\
& {\left[\mathrm{v}_{\mathrm{Co}}^{\prime \prime}\right] \propto\left(\mathrm{p}_{\mathrm{O}_{2}}\right)^{1 / 6}}
\end{aligned}
$$

The simplified electroneutrality condition

$$
\left[\hat{h}^{\circ}\right]=\left[\mathrm{v}_{\mathrm{Co}}^{\prime}\right]+2\left[\mathrm{v}_{\mathrm{Co}}^{\prime \prime}\right]
$$

was used in the derivation of eqs. (11-13). The deviation from stoichiometry is given by the relation

$$
\delta=\left[\mathrm{v}_{\mathrm{CO}}^{\mathrm{x}}\right]+\left[\mathrm{v}_{\mathrm{Co}}^{\prime}\right]+\left[\mathrm{v}_{\mathrm{Co}}^{\prime \prime}\right]
$$

If the mean lifetime of the various charged cation vacancies is small 
compared with the mean time-of-stay between vacancy jumps (1.e., the hole moblitty is much greater than the vacancy mobility), then only one jump frequency need be considered for all vacancies. If this jump frequency is independent of the defect concentration, then a measurement of the cation tracer diffusivity $\mathrm{D}^{*}$ as a function of $\mathrm{p}_{\mathrm{O}_{2}}$ may be related to $\delta$ and provide a determination of the dominant vacancy type.

- Several measurements of $\delta[7]$, electrical conductivity $[6,9,16]$ and $\mathrm{D}_{\mathrm{Co}}^{*}[13,14]$ cover a large range of $\mathrm{p}_{\mathrm{N}_{2}}$. These measurements show a curved plot vs $\mathrm{P}_{2}$, indicating that more than one type of tefect is present in $\mathrm{Co}_{1-\delta}$. The results of Dieckmann [13] for $n_{C o}^{*}$ are shown in Iig. 2 . Dieckmann has made an extensive analysis of the 1iterature data on the $\mathrm{PO}_{2}$ dependence of $\delta, \mathrm{D}_{\mathrm{Co}}^{*}$, and electrical conductivity. He concludes that the concentration of cobalt interstitials and oxygen vacancies are negligible; the dominant defects are vacancies on the cation sublattice and electron holes, and the vacancies can be formally treated as neutral, singly charged, or doub1y charged. The appropriate equilitrium constants for the reactions given by eqs. $(8-10)$ are as follows [13]:

$$
\begin{aligned}
& K_{8}=\frac{\left[V_{C o}^{x}\right]}{P_{C_{2}}^{I / 2}}=1.6 \times 10^{-2} \exp [-26,000(\mathrm{~J} / \mathrm{mol}) / \mathrm{RT}] ; \\
& \mathrm{K}_{9}=\frac{\left[\mathrm{V}_{\mathrm{Co}}^{\prime}\right]\left[\mathrm{h}^{\circ}\right]}{\left[\mathrm{v}_{\mathrm{Co}}^{\mathrm{x}}\right]}=2.4 \exp [-51,000(\mathrm{~J} / \mathrm{mol}) / \mathrm{RT}] \\
& \mathrm{K}_{10}=\frac{\left[\mathrm{V}_{\mathrm{Co}}\right][\dot{\mathrm{h}}]}{\left[\mathrm{V}_{\mathrm{Co}}^{\prime}\right]}=0.17 \exp [-72,000(\mathrm{~J} / \mathrm{mol}) / \mathrm{RT}] .
\end{aligned}
$$


The normalized $D_{C o}^{*}$ and electrical conductivity may be described by [13]

$$
\mathrm{D}_{\mathrm{Co}}^{*} / \Sigma\left[\mathrm{V}_{\mathrm{Co}}\right]=0.113 \exp [-136,00 \mathrm{~N}(\mathrm{~J} / \mathrm{mol}) / \mathrm{RT}]\left(\mathrm{csp}^{2} / \mathrm{s}\right)
$$

and

$$
\sigma /[\dot{\mathrm{h}}]=5.4 \times 10^{3} \exp \left[-R_{3} 600(\mathrm{~J} / \mathrm{mol}) / \mathrm{RT}\right](\Omega \cdot \mathrm{cm})^{-1}
$$

thus fustifying the earlier a sumption that the hole mobility is much greater than the vacancy mobility.

The curvature in the plots of $\log \mathrm{D}_{\mathrm{Co}}^{*}$ vs $\log \mathrm{P}_{2}$ shown in fig. 2 can be quantitatively interpreted in terms of a change in relative contributions of differently charged vacancles with varying $\mathrm{P}_{\mathrm{O}_{2}}$, as shown by Dieckmann [13]. Other possible interpretations of the data include (a) impurity-induced (extrinsic) defects at low $\mathrm{PO}_{2}$ and (b) defect clustering at high $\mathrm{P}_{2} \cdot$ Chen and Peterson $[21$ ? tave measured the isotope effect for $D_{C o}^{*}$ as a function of $\mathrm{PO}_{2}$ and observed values of $f \Delta K$ that are independent of $\mathrm{P}_{2}$ and consistent with diffusion by noninteracting vacancies and $\Delta \mathrm{K}=0.75$. Only the change in relative contribution of differently charged vacancies with varying $\mathrm{P}_{2}$ is consistent with the $\mathrm{P}_{2}$-inciependent value of f $\Delta K$. The other possible causas of curvature are expected to produce an observable $\mathrm{P}_{2}$-dependent value of $f \Delta K$ within the accuracy of the experiment; impurity-induced defects, defect clustering, and Frenkel defects do not make a major contribution to cation self-diffusion in $\mathrm{Co}_{1-\delta^{\circ}}$ at $1200^{\circ} \mathrm{C}$. Equation (19) indicates that $\mathrm{D}_{\mathrm{Co}}^{*} / \Sigma\left[\mathrm{V}_{\mathrm{Co}}\right]$ is independent of $\mathrm{P}_{\mathrm{O}_{2}}$ at a given temperature, 1.e., either all vacancies, independent of charge, move with the same activation energy $\left(h_{m}=136 \mathrm{~kJ} / \mathrm{mol}=32.5 \mathrm{ksal} / \mathrm{mol}\right)$ or on $1 \mathrm{y}$ one type of vacancy is mobile. It was previously mentioned that if the 
lifetimes of the various charged cation vacancies is inall as compared to the mean time of stay of a vacancy, the vacancy may change its charge state many thousands of times between jumps and only one activation energy corresponding to the energetically most favorable vacancy charge state is required to describe cation-vacancy exchange in $\mathrm{Co}_{1-\delta} \mathrm{O}$. The actual charge state of the vacancy during the jump is unknown. Without prior knowledge $\rightarrow$ of the vacancy charge state furing the jump process, potential gradient studies cannot be safely used to determine point defect concentrations or mobilities in a material like $\mathrm{Co}_{1-\delta^{O}}[13]$; theoretical calculations of this charge state will also be necessary for rellable calculations of activation energies for impurity diffusion.

Most of the features of the defect chemistry of $\mathrm{Co}_{1-\delta^{\circ}}$ are also applicahle to $\mathrm{NiO}$ and $\mathrm{Mn}_{1-\delta^{0}}$. The electrical-conductivity [17] and cation self-diffusion [18] measurements reculre both singly and doubly charged vacancies in $\mathrm{NiO}$, and $\mathrm{nly}$ one activation energy for defect migration $\left(h_{m}=150 \mathrm{~kJ} / \mathrm{mol}=36 \mathrm{kcal} / \mathrm{mol}\right)[17]$ seems appropriate. Self-diffusion and the isotope effect for cation migration 1 n $\mathrm{Mn}_{1-\delta^{0}}$ are consistent with migration by neutral, singly, and doubly charged vacancies; defect-defect interactions do not influence the diffusion until $\delta$ is greater than 0.01 [19]. Also, on]y one activation energy for defect migration seems appropriate in $\mathrm{Mn}_{1-\delta^{n}}$

\subsection{Results for impurity diffusion tin $\mathrm{HiO}$ and $\mathrm{Co}_{1-\delta^{\circ}} \mathrm{O}$.}

In addition to cation self-diffuston $[12,18,20-22]$, tracer diffusion has heen measured in Nin for the following impurities; Co $[12,22,23], \mathrm{Cr}$ 
[24], and $\mathrm{Fe}[12]$. The results for Impurity diffusion and self-diffusion (including anion self-diffusion [25]) in $\mathrm{NiO}$ at $\mathrm{p}_{\mathrm{O}_{2}}=0.21$ atm are shown in the form of Arrhenlus plots in fig. 3. The results for cation selfdiffusion and $\mathrm{Fe}$ impurity diffusion have heen adjusted to $\mathrm{P}_{2}=0.21$ atm from the $\mathrm{p}_{2}$ of measurement $\left(\mathrm{p}_{\mathrm{O}_{2}}=1\right.$ atm) using the relation $D \propto \mathrm{p}_{\mathrm{O}_{2}}^{1 / 6}$. Since the published results for ${ }^{35} \mathrm{~S}$ diffusion in Nio [26-28] may represent diffusion along dislocations or subboundaries [29], they are not included in fig. 3.

Tracer diffusion has been measured in $\mathrm{Co}_{1-\delta^{\circ}}$ for $\mathrm{Co}_{0}[5,11-13,22], 0$ [15], $\mathrm{Cr}[30], \mathrm{Fe}[12]$, and $\mathrm{N1}[12,22]$ 1ons. The results for impurity diffusion and self-diffusion in $\mathrm{Co}_{1-\delta^{\circ}}$ at $\mathrm{PO}_{2}=0.21$ atm are shown in the form of Arrhenius plots in fig. 4. The results for Fe impurity diffusion have been adjusted to $\mathrm{p}_{\mathrm{O}_{2}}=0.21$ at! from the $\mathrm{p}_{\mathrm{O}_{2}}$ of measurement $\left(\mathrm{P}_{2}=1 \mathrm{~atm}\right)$ using the relation $\mathrm{D} \propto \mathrm{p}_{\mathrm{O}_{2}}^{1 / 4}$. The published results for ${ }^{35} \mathrm{~S}$ diffusion in $\mathrm{Co}_{1-\delta^{0}}[28]$ are not included for the reasons given above for N10.

The activation energies for cation tracer diffusion in $\mathrm{NiO}$ and $\mathrm{Co}_{1-\delta^{\circ}}{ }^{\circ}$ are plotted versus lonic radius in fig. 5. The activation energy appears to vary systematically with the lonic radius if iron is a divalent ion in NiO and $\mathrm{CoO}$ in air. The lonic radius for $\mathrm{Fe}^{3+}$ is also shown in the figure. Iron ions in iron oxide in equilibrium in air are trivalent Ions. Apparently the bonding in $\mathrm{NiO}$ and $\mathrm{CoO}$ lowers the energy of the crystal. when the impurity is in the form of an $\mathrm{Fe}^{2+}$ ion rather than an $\mathrm{Fe}^{3+}$ 10n. 
Figure 5 also shows that the activation energy decreases when the Ionic radius increases; the larger the ton, the more rapidly it diffusas! This unexpected feature occurs in nearly all tracer impurity studies in oxides considered in this review. The reason for this unanticipated behavior is not obvious. A detalled calculation of $h_{m}^{i}, h_{f}^{1}$, and $c$ for a rumber of impurities in $\mathrm{NiO}$ or $\mathrm{COO}$ is a reasonable prohlem for the HADES program; such a calculation could provide considerable understanding of this unusual experimental observation.

The observed values of $\Delta O$ can be analyzed in terms of $\Delta h_{m}, \Delta h_{f}$ and $C$ for Co diffusion in $\mathrm{NiO}$ and to a lesser extent for $\mathrm{Cr}$ diffusion In NiO and $\mathrm{Co}_{1-\delta^{0}}$. First, we must establish vaiues of $0^{s}, h_{m}^{s}$, and $h_{f}^{s}$ for Nio. The value of $a^{5}$ is rather well established; Atkinson and Taylor $[20,21$ ! and Volpe and Reddy [18] have measured cation self-diffusion in NiO over nearly seven orders of magnitude and obtain $0^{S}$ in the range 58 to $60 \mathrm{kcal} / \mathrm{mol}$. We may take an average value of $59 \mathrm{kcal} / \mathrm{mol}$. Three measurements of $h_{f}^{s}$ provide a value of $19 \mathrm{kcal} / \mathrm{mol}[31-33]$. The preferred experimental value of $h_{m}^{s}$ is $37 \mathrm{kcal} / \mathrm{mol}[17]$. Since the value of $\mathrm{O}^{\mathrm{s}}$ is probably the most reliable, and the value of $h_{m}^{s}$ is probably the least rejiable, we have adjusted the values of $h_{f}^{s}$ and $h_{m}^{s}$ (Table I) to satisfy the relation $\sigma^{s}=h_{f}^{s}+h_{m}^{s}$. Since both singly and doubly charged vacancies may contribute to diffusion in Nio, one may expect the effective activation enthalpies to vary slightly with temperature and $\mathrm{PO}_{2} \cdot$ However, the observed constant value of $0^{8}$ over seven orders of magnitude in $D^{*}$ suggests that any temperature dependence of the effective activation enthalpies must be small in NiO. 
The effect of Impurity additions on impurity and self-diffusion in codoped N1O strongly suggests that the Co Ion-vacancy binding energy must be small [23] (see section 5). The value of $O^{1}$ for Co tracer diffusion in N10 1s $54 \mathrm{kcal} / \mathrm{mo}]$ [23]. The temperature dependence of the isotope effect for ${ }^{55} \mathrm{Co}$ and ${ }^{60} \mathrm{Co}$ diffusion in $\mathrm{N} 10$ gives $\mathrm{C}=-4 \mathrm{kcal} / \mathrm{mol}$ and an analysis of $\mathrm{C}$ suggests that $\Delta \mathrm{h}_{\mathrm{m}}$ is $-10 \mathrm{kcal} / \mathrm{mol}$ [23] (see section 5). This leads to the 'defect parameters for Co impurity diffusion in N1O stated in Table I, which are also consistent with the defect parameters for pure NiO. This suggests that the impurity-vacancy binding; energy may be small for homovalent impurities but the migration energy may be significantly different from that for self-diffusion.

Less extensive data exist for Cr trecer diffusion in NiO. The value of $n^{i}$ is $67 \mathrm{kcal} / \mathrm{mol}[24]$; thus $\Delta Q=8 \mathrm{kcal} / \mathrm{mol}$. Since $\mathrm{Cr}$ ions diffuse much slower than $\mathrm{Ni}$ lons in pure $\mathrm{NiO}$ [fig. 3], $\mathrm{w}_{2}$ must be much smaller than any other jump frequency, $f^{\mathcal{1}}$ must be nearly unity [see eq. (4)], and $c$ must he close to zero. If chromiun exists as $\mathrm{Cr}^{3+}$, there shouid be an attractive interaction hetween $\mathrm{Cr}^{3+}$ and charg:d vacancies, $1 . e ., \Delta \mathrm{h}_{f}$ will be negative. This suggests that $\Delta h_{m}$ must be greater than $8 \mathrm{kcal} / \mathrm{mol}$ ard $h_{m}^{1}$ must be greater than $47 \mathrm{kcal} / \mathrm{mol}$. Values of the $\mathrm{Cr}$ interdiffusion coef-

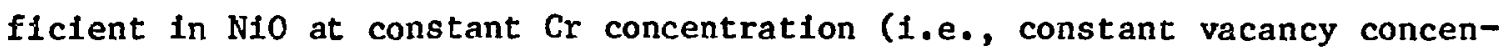
tration) suggest that $h_{m}^{1}-c-h_{b}^{1-V}$ is near 52 to $55 \mathrm{kcal} / \mathrm{mol}[34,35]$ (neglecting the temperature dependence of the thermodynamic factor). This suggests that $h_{m}^{1}$ for $\mathrm{Cr}^{3+}$ diffusion in $\mathrm{NiO}$ may be even greater than $55 \mathrm{kcal} / \mathrm{mol}$. 
The value of $0^{1}$ is $58 \mathrm{kcal} / \mathrm{mol}$ for Cr tracer diffuston 1 in Coo [30]; thus $\Delta O=20 \mathrm{kcal} / \mathrm{mol}$. For the same reasons listed above for Cr diffusion in $\mathrm{NiO}, \mathrm{C}$ must be close to zero and $\Delta \mathrm{h}_{\mathrm{f}}$ should be negative for $\mathrm{Cr}$ diffusion in $\mathrm{Co}_{1-\delta^{0}}$. This suggests that $\Delta \mathrm{h}_{\mathrm{w}}$ must be greater than $20 \mathrm{kcal} / \mathrm{mol}$. Taking $h_{\mathrm{m}}^{\mathrm{s}}=32.6 \mathrm{kcal} / \mathrm{mol}$ [eq. (19)], one obtains $h_{\mathrm{m}}^{1}$ greater than $52 \mathrm{kcal} / \mathrm{mol}$ for $\mathrm{Cr}$ ions in $\mathrm{Co}_{1-\delta^{0}}$. This suggests that morlest sized binding energies may be expected for trivalent impurities in a divalent matrix and the migration energy may be much larger than that for self-diffusion.

\section{Impurity Diffusion in $\mathrm{Fe}_{3} \mathrm{O}_{4}$}

\subsection{Defect structure and cation self-diffusion in $\mathrm{Fe}_{3} \mathrm{O}_{4}$}

Magnecite $\left(\mathrm{Fe}_{3} \mathrm{O}_{4}\right)$ exists in the inverse spinel structure at low temperatures and is a metal-deficient oxide relative to the stoichiometric composition [36] at all hut the lowest $\mathrm{P}_{\mathrm{O}_{2}}$ for which the phase is stabie $[37,38]$; the deviation from stoichionetry increases with increasing $\mathrm{P}_{2}$. At low temperatures, one-eighth of the 64 cation tetrahedral sites and onefourth of the 32 cation octahedral sites in the unit cell are occupied by $\mathrm{Fe}^{3+}$ ions whlle one-fourth of the octahedral sites are occupled by $\mathrm{Fe}^{2+}$ 10us $[39,40]$. At higher temperatures electron interchange occurs, leading to a random distribution of the $\mathrm{Fe}^{2+}$ and $\mathrm{Fe}^{3+}$ lons among the occupled tetrahedral and octahedral sites [4!].

Dieckmann and Schmalzried [42] recently reported measurements of $\mathrm{D}_{\mathrm{Fe}}^{*}$ in $\mathrm{Fe}_{3} \mathrm{O}_{4}$ that show a minimum in the plot of $\log \mathrm{D}_{\mathrm{Fe}}^{*}$ versus $\log \mathrm{p}_{\mathrm{O}_{2}}$, as seen in fig. 6. These results may he explained in terms of the following model 
[38]: At low $\mathrm{PO}_{2}$, where $\mathrm{Fe}_{3} \mathrm{O}_{4}$ is stoichiometric, the 1ntrinsic defects are Frenkel pairs; thus, iron diffusion is dominated by the more mobile iron Interstitial ions. As $\mathrm{PO}_{2}$ increases, and vacancles form on the iron sublattice [37], the iron intersticla] fon concentration decreases, causing $D_{\mathrm{Fe}}^{*}$ to decrease. However, as $\mathrm{P}_{2}$ continues to increase, a point is reached beyond which the vacancy component completely dominates the diffusion process; from that point on, $\mathrm{D}_{\mathrm{Fe}}^{*}$ increases with increasing $\mathrm{P}_{2}$.

This model may be stated in terms of reactions involving vacancies on octahedral $\left(v_{0}\right)$ or tecrahedral $\left(v_{\mathrm{F}}\right)$ sites and iron ions of two different charge states on interstitial sites ( $\mathrm{Fe}_{\mathrm{I}}^{3+}, \mathrm{Fe}_{\mathrm{I}}^{2+}$ ). For sufficiently small point-defect concentrations, one obtains the relations

$$
\left[v_{0}\right] \propto\left[v_{T}\right] \propto\left(p_{O_{2}}\right)^{2 / 3}
$$

and

$$
\left[\mathrm{Fe}_{\mathrm{I}}^{2+}\right] \propto\left[\mathrm{Fe}_{\mathrm{I}}^{\mathrm{H}}\right] \propto\left(\mathrm{p}_{\mathrm{O}_{2}}\right)^{-2 / 3}
$$

The results of Dieckmann and Schmalzried [42] (Fig. 6) show a slope a $\log \mathrm{D}_{\mathrm{Fe}}^{*} / \partial \log \mathrm{P}_{\mathrm{O}_{2}}=-2 / 3$ at $\operatorname{low} \mathrm{P}_{\mathrm{O}_{2}}$, as suggested by eq. (22) if the defect mobility is independent of $\mathrm{PO}_{2}$. At high $\mathrm{PO}_{2}$ a slope near $+2 / 3$ is observed, as expected from ea. (21). A model with a randon vacancy distribution between the tetrahedral and octahedral sites is entirely consistent with the data.

Peterson et al. [43] have recently measured $D_{F e}^{*}$ and the isotope effect for cation self-diffusion as a function of $\mathrm{PO}_{2}$ at $1200^{\circ} \mathrm{C}$ in $\mathrm{Fe}_{3} \mathrm{O}_{4}$ in order 
to differentiate between the free-interstitial mechanism and the interstitialcy mechanism at lower $\mathrm{P}_{2}$ and to verify the inportance of the vacancy mechanism at higher $\mathrm{P}_{2}$. The isotope-effect results at the higher $\mathrm{P}_{2}$ levels are entirely consistent with diffusion by the vacancy mechanfsm. The isotope effect at the lower $\mathrm{P}_{\mathrm{O}_{2}}$ levels (interstitial region) is ahout half that at the higher ievels. Since the correlation Tactor for diffusion by free interstitials is generally larger than for vacancles, the smaller value of the isotope effect at the two lower $\mathrm{PO}_{2}$ values must arise principally from a two-atom jump process. Thus, the Interstitial-type mechanism at lower $\mathrm{P}_{\mathrm{O}_{2}}$ must be an interstitialcy mechanism.

Peterson et al. [43] evaluated the correlation factor for two types of vacancy jumps (tetrahedral and octahedral sublattice) and seven types of interstitialcy jumps in $\mathrm{Fe}_{3} \mathrm{O}_{4}$. Two different types of jumps involving the normally occupied tetrahedral sites are shown in fig. 7 ; the positions of the oxygen lons have been omitted from the figure for clarity. In mechanism (1), a vacancy can jump to any one of its four nearest-neighbor occupied sites. In mecianism (2), an interstitial ion at position 1 jumps into the normally occupied tetrahedral site at position 0 and the 1 on at position 0 jumps into interstiticl site 2 , ? or 4 . The interstitial sites in mechanism 2 are normallv unoccupled octahedral sites. The fumps in mechanism 2 are "dog-leg" or noncollinear interstitialcy jumps involving the simultaneous motion of two atoms. (For a description of the vacancy 
Jumps on the octaheriral suhlattice and the other sir types of interstitialcy fumps considered, as well as the calculation of the correitation factor for these fumps, see ref. 43.)

Poth types of vacancy jumps are consistent with the isotope effect results with $\Delta K$ near unity, and $f^{\prime}$ ve or the seven interstitialcy jumps are consistent with the isotope effect results. On the basis of the available space and location of itoms in the lattice, one might guess that unoccupled octahedral sites are the most likely interstitlal sites for interstitialcy diffusion on both the tetrahedral and octahedral sublattice of $\mathrm{Fe}_{3} \mathrm{O}_{4}$. Under these conditions, the interstitialcy mechanism shown in fig. 7 is the most probable interstitial-type mechanism in $\mathrm{Fe}_{3} \mathrm{O}_{4^{\circ}}$

\subsection{Results for Impurit; diffusion in $\mathrm{Fe}_{3} \mathrm{O}_{4}$}

Tracer impurity diffusion has been measured for ${ }^{60} \mathrm{Co}$ and ${ }^{51} \mathrm{Cr}$ in $\mathrm{Fe}_{3} \mathrm{O}_{4}$ [44]. The plots of $\log \mathrm{D}^{*}$ vs $\log \mathrm{P}_{2}$ show a minimum (see fig. 8), as observed for cation self-diffusion. The minimum occurs at nearly the same $\mathrm{P}_{2}$, and $\partial \log \mathrm{D}^{*} / \partial \log \mathrm{P}_{\mathrm{O}_{2}}$ is the same, for both impurity diffusion and self-diffusion [44]. This implies that the impurities diffuse by the same defect mechanism responsible for self-diffusion. This is easy to see for higher $\mathrm{PO}_{2}$ where the vacancy mechanism is responsible for self-diffusion; only the vacancy concentration varles with $\mathrm{p}_{2}$, so a $\log \mathrm{D}^{*} / \partial \log \mathrm{P}_{2}$ may be expected to be the same for both impurity and self-diffusion. For the same interstitial-type defect to be responsible for both impurity and selfdiffusion, a two-atom process (1.e., an interstitialcy mechanism) must be 
involved. Thus, the mechanism of diffusion renulred by the isotope effect measurements for self-diffusion is entirely consistent with the impuritydiffusion data for $\mathrm{Fe}_{3} \mathrm{O}_{4}$. Th1s suggests that for those systems where a $\log \mathrm{D}^{*} / \mathrm{a} \log \mathrm{P}_{2}$ for self-iffusion requires an interstitial-type mechanism, a similar measurement for impurity diffusion should yield an identical value of $a \log \mathrm{D}^{*} / \partial \log \mathrm{P}_{\mathrm{O}_{2}}$ if an interstitialcy mechantsm is operating but may yleld a different value of the slope for Impurity diffusion if an interstitial mechanism is responsihle for self -diffusion. As in the case of impurity diffusion in CoO and N1O, the smailer impurity $\mathrm{Cr}$ diffuses much slower (by a factor of 2 to 3 orders of magnitude) than the larger i.upurity Co. The similarity in the diffusion behavior of ${ }^{60} \mathrm{Co}$ and ${ }^{59} \mathrm{Fe}$ may suggest that tracer diffusion of $\mathrm{Fe}$ in $\mathrm{Fe}_{3} \mathrm{O}_{4}$ is governed primarily by the motion of $\mathrm{Fe}^{2+}$. The slow migration of ir may reflect the migration rate of $\mathrm{Fe}^{3+}$. The high mobillty of the electron holes allows any given Fe Ion to change charge states many times between jumps. Thus the Fe fon will jump primarily when it is $i_{i i}$ the more mobile charge state $\left(i . e ., \mathrm{Fe}^{2+}\right)$.

Dieckmann et al. [44] have also di luced an "apparent motion enthalpy," equal to $h_{m}^{i}-c-h_{b}^{1-v}$ in the present notation of eq. (5), for diffusion in the vacancy regime in $\mathrm{Fe}_{3} \mathrm{O}_{4}$. They obtain $32.9 \mathrm{kcal} / \mathrm{mol}$ for ${ }^{59} \mathrm{Fe}$, $32.9 \mathrm{kcal} / \mathrm{mol}$ for ${ }^{60} \mathrm{Co}$, and $58.8 \mathrm{kcal} / \mathrm{mol}$ for ${ }^{51} \mathrm{Cr}$ migration in $\mathrm{Fe}_{3} \mathrm{O}_{4}$. 


\section{Impuricy Diffusion in $\mathrm{TiO}_{2}$}

\subsection{Atomfic and defect structure of $\mathrm{T}: \mathrm{O}_{2}$}

The crystal scructure of rutile $\left(\mathrm{TiO}_{2}\right)$ is noncubic and may be seen in fig. 9. The sublattice of the $\mathrm{Ti}^{4+}$ ions is body-centered tetragonal. The struciure may be viewed as consisting of $\mathrm{TiO}_{6}$ octahedra sharing edges and corners in such a way that each oxygen ion belongs to three neighboring octahedra. The oxygen octahedra are slightly distorted. When two unit cells are placed side by side and observed paraliel to the craxis, open channels become apparent, fig. 9b; open channels perpendicular to the $c-$ a is are not apparent. The open channels will cause anisotropy in the diffusion process and may allow fast diffusion of smaller ions parallel to the c-axis.

The dominant defects in 'rutile are still under discussion even though numerous studies using a variety of techniques have been reported in the 1iterature. Data supporting oxygen vacancies, $v_{0}$, or titanium interstitials, $\mathrm{Ti}_{1}$, may be found. Kofstad [45] first proposed a defect model comprising both doubly charged oxygen vacancies and interstitiaj titanium Ions with three and four effect charges. He suggests that $v_{0}$ predoninates at high oxygen partial pressures and low temperatures whereas $\mathrm{Ti}_{1}^{3+}$ and $\mathrm{I}_{1}^{4+}$ are suggested as dominant defects at higher temperatures and lower oxygen pressure. Recent conductivity and thermogravimetry measurements by Marucco [46] further support this model, and suggest the additional possibility that singly charged oxygen vacancies $v_{0}^{\prime}$ become important at the highest 
$\mathrm{P}_{2}$. Both cation tracer diffusion [47] and proton channeling [48] experiments demonstrate that the predominant defect of the metal sublattice is the titanium interstitial.

\subsection{Impurity diffusion in $\mathrm{NiO}_{2}$}

As noted above, oper channels exist parallel to the c-axis in $\mathrm{TiO}_{2}$, and may allow fast diffusion of small impurity ions. Making certain as-sumptions about the degree of ionicity of the Ti-O bond and using Pauling's ionic and covalent radii for $T i$ and 0 , Witke [49] estimates the interstitial diffusion channels to consist of chains of "volds" of approxinately $0.77 \AA$ radius, joined by deformed. regions of comparable cross-sectional area :

Johnson [50] was the first to measure the migration of a small ion, $\mathrm{LI}^{+}\left(\mathrm{r}_{1}=0.62 \AA\right)$, in $\mathrm{TiO}_{2}$. He ohserved that lithium diffusion parallel to the c-axis (along the direction of the open channels) is at least $10^{8}$ times faster than perpennicular to the c-axis. A good Arrhenlus plot was observed for $D_{\| c}$ with $D_{0} \sim 0.3 \mathrm{~cm}^{2} / \mathrm{sec}$ and $Q_{\| c}=7.6 \mathrm{kcal} / \mathrm{mol}$. This gives $D_{\| c}^{\mathrm{Li}} \sim 10^{-3} \mathrm{cn}^{2} / \mathrm{sec}$ at $\mathrm{T} \sim 500^{\circ} \mathrm{C}$ compared to an extrapolated value of $\mathrm{D}_{\mathrm{Ul}}^{\mathrm{Ti}} \sim 10^{-18} \mathrm{~cm}^{2} / \mathrm{sec}$ at a similar temperature. Although an indirect method (optical absorption) was used to determine $\mathrm{D}^{\mathrm{LI}}$ and $\mathrm{LI}$ was present in bulk quantities (hence, diffusion in a chemical gradient was measured), the large value of $D_{H c}^{\mathrm{LI}}$, the small value of $O_{H c}$, and the large anisotropy are strong support for the channel model and interstitial diffuston. The channel mechanism presumably works best in an ideal crystal (unlike most 
diffusion mechanisms). Iohison [50] has observed that Li diffugion in $\mathrm{TiO}_{2}$ was strongly influenced by ahraston of the surface. Since dislocations or stacking faults introduced by grinding may close off channels, these observations further support the channel model of diffusion.

Another small interstitial impurity atom, $H$, also shows rapid diffusion $\left(D_{\mathrm{lc}}^{\mathrm{H}} \sim 3 \times 10^{--7} \mathrm{~cm}^{?} / \mathrm{sec}\right.$ at $\left.\mathrm{T}=500^{\circ} \mathrm{C}\right)$ and considerable anisotropy in the diffusion coefficients [51] $\left(\mathrm{D}_{\mathrm{HC}}^{\mathrm{H}} / \mathrm{D}_{\mathrm{LC}}^{\mathrm{H}} \sim 150\right.$ at $\left.\mathrm{T}=500^{\circ} \mathrm{C}\right)$ in $\mathrm{TiO}_{2}$. However, owing to the interaction of the $\mathrm{H}^{+}$with oxygen ions, the mechanism of migration of $\mathrm{H}^{+}$may be more complicated and involve the iormation, rotation, and dissociation of oH [52].

Wittke [49] has made qualitative observations of color change in T1O, crystals which suggest that $\mathrm{Cr}, \mathrm{Fe}, \mathrm{Co}$, and $\mathrm{NI}$ diffuse rapidly along the caxis. Similar qualitative ohservations have been reported by steele and McCartney [53] which support the conclusion that $\mathrm{D}_{\mathrm{ll}}^{\mathrm{Fe}}>\mathrm{D}_{1 \mathrm{C}}^{\mathrm{Fe}}$ in $\mathrm{TiO}_{2}$. One may expect $\mathrm{Cr}^{3+}(0.62 \AA), \mathrm{Fe}^{3+}(0.65 \AA), \mathrm{Co}^{2+}(0.74 \AA)$, and $\mathrm{Ni}^{2+}(0.69 \AA)$ to liffuse rapidly through the $0.77 \AA$ channels, in contrast to oxygen or larger impurities.

Sasaki and Peterson [54] have macie preliminary tracer diffusion studies of ${ }^{60} \mathrm{Co}$ and ${ }^{51} \mathrm{Cr}$ in $\mathrm{TiO}_{2}$, both parallel and perpendicular to the $\mathrm{c}$ axis. They observe that $D_{\| C}^{C o}$ is about $10^{7}$ times greater than $D_{\| C}^{T 1}$ (at $800^{\circ} \mathrm{C}$ ) with $D_{0}=3.9 \mathrm{~cm}^{2} / \mathrm{sec}$ and $0=33 \mathrm{kcal} / \mathrm{mol}$. The value of $D_{L C}^{C o}$ is not as well

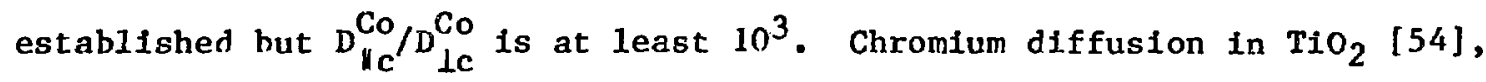
like cation self-diffusion [55], shows relatively little anisotropy. However, even though $\mathrm{Cr}^{3+}$ is nearly $20 \%$ smaller than $\mathrm{Co}^{2+}, \mathrm{D}_{\mathrm{NC}}^{\mathrm{Co}} \times 10^{5} \mathrm{D}_{\mathrm{UC}}^{\mathrm{Cr}}$ in 
$\mathrm{TIO}_{2}$. It is clear that ionic size alone is not a good criterion for rapid diffusion along the open channels in $\mathrm{TiO}_{2}$. More extensive tracer inpurity diffusion studies and state-of-the-art calculations will be needed before the effects of lonic size and charge on rapid diffusion in the open channels of $\mathrm{TiO}_{2}$ are understood.

\section{.5. Effect of Impurities on Diffusion}

\subsection{Cobalt inpurity diffusion in NiO}

The presence of an impurity aton in an otherwise pure crystal will change the jump frequencles of the nelghboring solvent atom relative to the values in the absence of the impurity. The correlation factor for impurity ij.ffusion $f^{i}$ must be stated in terms of a number of different jump frequencles, as shown in ea. (4) (fig. 1). For each impurity atom added to the solvent, a known number of solvent atoms will jump with a frequency $w_{1}$, $w_{3}$, or $w_{4}$ rather than $w_{0}$. Lidjard [56] was the first to derive the average solvent-atom jump frequency as a function of Impurity content $c$ in terms of the various $w_{i}^{\prime} s$. He found that the self-diffusion coefficient in an alloy of composition $c, \mathrm{D}^{\mathrm{S}}(\mathrm{c})$, could be written as

$$
D^{S}(c)=D^{S}(0)(1+b c)
$$

where $D^{S}(0)$ is the solvent ion diffusion coefficient in the pure solvent. The enhancement factor $b$ is expressed by

$$
b=-18+4\left[\frac{w_{1}}{w_{0}}+\frac{7}{2} \frac{w_{3}}{w_{0}}\right] \exp \left(h_{b}^{i-v} / k T\right)
$$


within the framework of the Lidiard theory. Here, the Impurity vacancy binding energy $h_{b}^{d-v}$ may be expressed in terms of the jump frequency ratio

$$
w_{4} / w_{3}=\exp \left(h_{b}^{1-v} / k T\right)
$$

The ratio of the impurity diffusion coefficient $D^{i}(0)$ to the solvent diffusion coefficient in the otherwise pure solvent is given by [56]

$$
\frac{D^{i}(o)}{D^{s}(o)}=\frac{f^{i}}{f^{s}} \frac{w_{2}}{w_{o}} \exp \left(h_{b}^{i-v} / k T\right),
$$

where $f^{S}$ is the correlation factor for solvent self-diffusion. Thus, from the experimentaliy measured quantities $f^{1}, b$, and $D^{1}(0) / D^{s}(0)$, one obtalns information abuut the various jump processes near an impurity ion.

In deriving eq: (24), Lidlard assumed that all solvent jumps in the ailoy have a correlation factor $f^{S}$ as in the pure solvent. Howard and Manning [57] have removed this assumption and found that, for a given set of values of $D^{i}(0), D^{s}(o)$, and $b$, a range of possible values of $f^{i}$ exist, and that unique values of $w_{4} / w_{0}, w_{3} / w_{1}$, and $w_{2} / w_{1}$ correspond to each value of $f^{i}$. Hence, given experimental values of $D^{i}(0), I^{s}(0), b$, and $f^{i}$, a unique set of jump-frequency ratios may be obtained. Experiments of this type have been performed for Impurity diffusion in metals [58-60]; however, for the following discussions, Lidiard's theory will be sufficient.

In an attempt to study the letailed process of cation impurity diffustion and the effect of Impurity-defect interactions on cation selfdiffusion in oxides, Chen and Peterson [23] have measured the isotope effect for cobalt diffusion in $\mathrm{N} O \mathrm{O}$ and the dependence of cobalt and nickel 
diffusivities on dilute cohalt concentrations in $\left(\mathrm{Ni}_{1-\mathrm{c}} \mathrm{Co}\right.$ ) $\mathrm{O}$ crystals. The experimental values of $(f \Delta K)_{C o}$, deduced from measurements of the simultaneous diffusion of ${ }^{55} \mathrm{Co}$ and ${ }^{60} \mathrm{Co}$ in $\mathrm{NiO}$, increase from $0.45 \pm 0.01$ at $1179^{\circ} \mathrm{C}$ to $0.61 \pm 0.01$ at $1649^{\circ} \mathrm{C}$. The correlation factor $\mathrm{f}_{\mathrm{Co}}$ was determined from the product ( $f \Delta K)_{C o}$ by assuming that $\Delta K$ for cobalt impurity diffusion is the same as that for nickel self-diffusion in $M i n(\Delta K=0.78)$, and $f_{C o}$ is plotted as a function of temperature in $f i g .10$. The slope of the line in fig. 10 gives $C=-4 \mathrm{kcal} / \mathrm{mol}$, a value used in Section 2.3 and Table I.

The diffusion coefficients for both cobalt and nickel diffusion in (Ni $\left.{ }_{1-c} \mathrm{Co}_{c}\right) 0$ crystals increase linearly with cobalt concentrations (up to $c=0.015)$ at precisely the same rate. The equal enhancement for both solvent and solute diffusion is further demonstrated by the fact that the ratios of $\mathrm{D}_{\mathrm{Co}} / \mathrm{D}_{\mathrm{N1}}$, obtained from the simultaneous diffusion of ${ }^{60} \mathrm{Co}$ and ${ }^{57} \mathrm{Ni}$, are independent of composition at a given temperature.

Lidiard's theory has successfully explained the effect of solute additions on self-diffusion in many metallic systems; however, it does not predict the enhancement of solute diffusivity. Fy extending Lidiard's analysis, one can show that the association of a vacancy with two solute atoms may result in a linear enhancement for solute diffusion, and wil acid a auadratic term to the expression for the enhancement of the solvent diffusivity [3]. Thus both solvent and solute diffusion may be enhanced by additions of solute, hut the enhancement effect for solvent diffusion 
should be greater than that for solute diffusion. This prediction is concrary to the experimental results for the $\left(\mathrm{NI}_{1-\mathrm{c}} \mathrm{Co}_{\mathrm{c}}\right) \mathrm{O}$ crystals.

In addicion to the effects of solute additions on self-diffusion conEidered by Lidiard for metallic systems, an effect in oxide systems arises from charge neutrality conditions. Since the third ionization energy for $\mathrm{Co}^{3+}$ is lower than that for $\mathrm{Ni}^{3+}$, the concentration of cation vacancies must vary at a given temperature in a dilute oxjde solid solution to conserve charge neutrality. This will cause the free-vacancy concentration to vary linearly with cation composition. 'The combined effect of the vacancy-solute interactions given hy Lidiard and the change in free-vacancy concentration result in the enhancement factors $b_{1}=b+b_{V}$ and $B_{1}=h_{V}$ for the diffusion of solvent and solute, respectively. Here $b_{V}$ is the contribution to the enhancement of diffusivity due to increased free-vacancy concentration. Since the experimental results show that $b_{1}=R_{1}$ and $D^{i} / D^{S}$ are constant values independent of co concentration at a given temperature, the enhancement of both cobalt and nickel diffusion is primarily caused by the increased concentration of cation vacancies; the vacancy-solute interactions and their contribution to the erhancement of solvent diffusion are negligible $(b$ : 0$)$.

These conclusions suggest that $h_{b}^{i-v} \ll k T$ and $w_{0}=w_{1}=w_{3}=w_{4} \neq w_{2}$. Using these conditions, $w_{2} / w_{0}$ and $\mathrm{D}_{\mathrm{Co}} / \mathrm{D}_{\mathrm{Ni}}$ in pur= iijo were calculated as a function of temperature from only the measured values of $r_{\text {Co }}$ using eqs. (4) and (26). The calculated values of $w_{2} / w_{0}$ and $D_{C o} / D_{N 1}$ are plotted versus temperature in fig. 11. The tempe:ature dependence of $w_{2} / w_{0}$ guves directly 


\section{Reference6}

[1] A. D. LeClaire, In: Physical chemistry, Vol. 10, eds. H. Eyring, D. Henderson and W. Jost (Academic Press, N.Y.), Chapter 5.

[2] J. R. Manning, Phys. Rev. 136 (1964) Ali58.

[3] A. D. LeCla1re, J. Nucl. Mat. 69\&7n (1978) 70.

[4] P. kofstad, in: Nonstoichiometry, diffusion, and electrical conductivity in binary metal oxides ( $J$. Wiley \& Sons, New York, 1972).

[5] R. F. Carter and F. D. Richardson, Trans. AIMF 200 (1954) 1244.

[6] P. Fisher and D. S. Tannhauser, J. Chem. Phys: 44 (1966) 1663.

[7] H.-G. Sockel and H. Schmalzried, Ber. Bunsenges. Phys. Chem. 72 (1968) 745 .

18] N.. G. Eror and J. B. Wagner, Jr., J. Phys. Chem. Solids 29 (1968) 1597.

[9] I. Bransky and J. M. Wimmer, J. Phys. Chem. Solids 33 (1972) 801 .

[10] E. Fryt, Oxid. Met. 10 (1976) 311.

[11] W. K. Chen. N. I. Peterson and W. T. Reeves, thys. Rev. 186 (1969) 887.

112] W. P. Crow, Ph.D. Thesis, Ohio State Untversity (1969).

[13] R. Dieckmann, 7. Phys. Chem. Neue Folge 107 (1977) 189.

[14] W. K. Chen and I. I. Peterson, J. Phys. Chen, Solids 41 (1980) 647.

[15] J. K. Chen and R. A. Jackson, J. Phys. Chem." Solids 30 (1969) 1309.

[16] M. Gvish1 and D. S. Tannhauser, J. Phys. Chem. Sollds 33 (1972) 893. 
117! R. Farhi and G. Petot-Frvas, J. Phys. Chem. Solids 39 (1978) 1169; ibld. 39 (1978) 1175.

[18] M. I. Volpe and J. Reddy, J. Chem. Phys. 53 (1970) 1117.

[19] N. L. Peterson and V. F. Chen, J. Phys. Chem. Sollds 43 (1982) 29.

[20] A. Atkinson and R. I. Taylor, J. Mater. Sc1. 13 (1978) 427.

[21] A. Atkinson and R. I. Taylor, Phil. Mag. A 39 (1979) 581.

[22] W. K. Chen and N. L. Peterson, J. Phys. Chem. Solids 34 (1973) 1093.

[23] W. K. Chen and N. I. Peterson, J. Phys. Chem. Solids 33 (1972) 881.

[24] W. K. Chen, N. L. Peterson and L. C. Robinson, J. Phys. Chem. Solids 34 (1973) 705.

[25] C. Dubois, Pk.D. Thests, Untversity of Paris (1979).

[26] D. R. Chang, R. Nemoto, and J. B. Wagner, Jr., Met. Trans. 7A (1976) 803.

[27] W.-Y. Fowng and J. R. Wagner, Jr., J. Phys. Chem. Solids 39 (197:5) 1019.

[28] P. Dumas, A. Fauvre, and J. C. Colson, Ann. Chim. (Paris) 4 (1979) 269.

[29] J. Sasak1 and N. L. Peterson, unpublished results (1982).

[30] W. K. Chen, unpihlished results (1982), and W. K. Chen, N. L. Peterson and G. J. Talaber, Bull. Am. Ceram. Soc. 60 (1981) 375.

[31] C. M. Osburn and R. W. Vest, J. Phys. Chem. Solids 32 (1971) 1331.

[32] Y. D. Tretyakov and R. A. Rapp, Trans. AIME 245 (1969) 1235.

[33] W. C. Tripp and N. M. Tallan, J. Am. Ceram. Soc. 53 (1970) 531.

[34] C. Greskovick, J. Am. Ceram. Soc. 53 (1970) 498. 
[35] R. A. Perkins, Ph.D. Thesis, Ohio State University (1971).

[36] L. S. Darken and R. W. Gurry, J. Am. Ceram. Soc. 68 (1946) 798 .

[37] H. G. Sockel and H. Schmalzried, Rer. Punsenges. Phys. Chem. 72 (1968) 745.

[38] R. Dieckmann and H. Schmalzried, Ber. Bunsenges. Phys. Chem. 81 (1977) 414.

[39] F. J. W. Verwey, P. W. Honyman and F. C. Romeijn, J. Chem. Phys. 15 (1947) 181

[40] C. P. Shull, E. 0. Wollman and W. C. Koehler, Phys. Rev. 84 (1951) 912.

[41] C. C. Wu and T. O. Mason, J. Am. Ceram. Soc. 64 (1981) 520.

[42] R. Dieckmann and H. Schmalzried, Ber. Bunsenges. Phys. Chem. 81 (1977) 344 .

[43] N. L. Peterson, W. K. Chen and D. Wolf, J. Phys. Chem. Solids 41 (1980) 709.

[44] R. Dieckmann, I.. 0. Mason, J. D. Hodge, and H. Schmaleried, Ber. Bunsenges. Phys. Chem. 82 (1978) 778.

[45] P. Kofstad, J. Less-Common Metals 13 (1967) 635.

[46] J.-F. Marucco, J. Gautron and P. Lemasson, J. Phys. Chem. Solids 42 (1981) 363.

[47] J. R. Akse and H. R. Whitehurst, J. Phys. Chem. Solids 39 (1978) 457.

[48] E. Yag1, A. Koyama, H. Sakairi and R. Hasigut1, J. Phys. Soc. Japan 4. (1977) 939.

[49] J. P. Wittke, J. Filectrochem. Soc. 113 (1966) 193. 
[50] 0. W. Johnson, Phys. Rev, 136 (1964) A284.

I51] 0. W. Johuson, S. -H. Paek and J. W. DeFord, J. App1. Phys. 46 (1975) 1026.

[52] J. R. Rates, J. C. Wang and R. A. Perkins, Phys. Rev. B19 (1979) 4130.

[53] J. L. Steele and E. R. McCartney, Nature 222 (1969) 79.

i54] J. Sasaki and N. L. Peterson, work in progress, 1982.

[55] T. S. Lundy and W. A. Coghlan, J. Phys. Paris 34 (1973) C9-299.

[56] A. B. Lidiard, Phil. Mag. 5 (1960) 1171.

[57] R. E. Howard and J. R. Manning, Phys. Rev. 154 (1967) 561.

[58] S. J. Rothman and N. L. Peterson, Phys. Rev. 154 (1967) 552.

[59] N. L. Peterson and S. J. Rothman, Phys. Rev. 154 (1967) 558.

160] N. L. Peterson and S. J. Rothman, Phys. Rev. B2 (1970) 1540. 
Table I. Probable values of defect parameters in Nio (all values in $\mathrm{kcal} / \mathrm{mol}$ ).

\begin{tabular}{lcr} 
(a) Se: $i^{\varepsilon}-$ Diffusion & \\
\hline$n^{5}$ & $h_{\mathrm{f}}^{6}$ & $\mathbf{h}_{\mathrm{m}}^{\mathrm{s}}$ \\
59 & 20 & 39
\end{tabular}

(b) Impurity Diffusion

$\begin{array}{crrcrr}\text { Impurity } & 0^{i} & h_{\mathrm{f}}^{i} & \mathbf{h}_{\mathrm{h}}^{i-\mathrm{v}} & \mathbf{h}_{\mathrm{m}}^{i} & \mathrm{C} \\ \text { Co } & 54 & 21 & \sim 0 & 29 & -4 \\ \text { Cr } & 67 & <20 & >0 & >47 & 0\end{array}$




\section{Figure Captions}

Fig. 1. Vacancy fumps near an Impurity in an fcc crystal.

Fig. 2. Cation self-diffusion as a function of the oxygen partial pressure In $\mathrm{Co}_{1}-\delta^{\circ}$ in the temperature range $1000-1400^{\circ} \mathrm{C}$. From Dieckmann [13].

Fig. 3. Tracer diffusion in $\mathrm{NiO}$ at $\mathrm{PO}_{2}=0.21$ atm. The data are from the following references: ${ }^{55} \mathrm{Fe}-\mathrm{Crow}[12] ;{ }^{60} \mathrm{Co--Chen}$ and Peterson $[22,23]$; high-temperature ${ }^{63} \mathrm{Ni}$-Volpe and Reddy [18] and Chen and Peterson [22]; 1ow-temperature 63w-Atkinson and Taylor $[20,21]$; ${ }^{51} \mathrm{Cr}$-Chen, Peterson and Robinson [24]; ${ }^{18} 0$--Dubois [25].

FIg. 4. Tracer diffusion in $\mathrm{Co}_{1-\delta^{O}}$ at $\mathrm{P}_{0_{2}}=0.21$ atm. The data are from the following references: ${ }^{60}$ Co--Carter and Richardson [5], Chen, Peterson and Reeves [11], Chen and Peterson [22], and Dieckmann

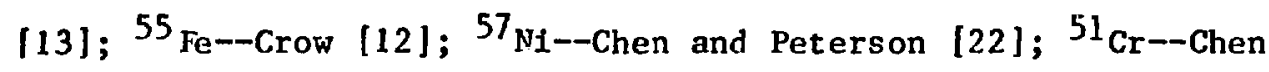
$[30] ;{ }^{18} 0--C h e n$ and Jackson [15].

Fig. 5. Activation energy for tracer diffusion in $\mathrm{NiO}$ and $\mathrm{Co}_{1-\delta^{O}} \mathrm{vs}$ ionic radius of the tracer ion.

FIg. 6. The cation self-iffusion coefficient in $\mathrm{Fe}_{3} \mathrm{O}_{4}$ as a function of $\mathrm{P}_{\mathrm{O}_{2}}$ in the temperature range $900-1400^{\circ} \mathrm{C}$. From Dieckmann and Schmalzried [42]. 


\section{Flgure Captions (continued)}

FIg. 7. Vacancy and interstitialcy iumps mainly involving cation tetrahedral sites in the $\mathrm{Fe}_{3} \mathrm{O}_{4}$ lattice. The oxygen sites are omitted for clarity. From peterson et al. [43].

Fig. 8. Tracer diffusion in $\mathrm{Fe}_{3} \mathrm{O}_{4}$ as a function of the oxygen partial pressure at $1200-1210^{\circ} \mathrm{C}$. The data are from the following references; ${ }^{59}$ Fe--Dieckmann and Schmalzried $[42] ;{ }^{60} \mathrm{Co}$ and ${ }^{51} \mathrm{Cr}$ Dieckmann, Mason, odge, and Schmalzried [44].

Fig. 9. (a) A unit cell of the rucile $\left(\mathrm{TiO}_{2}\right)$ structure. (b) An end view of the atomic arrangement for the [001] axial direction. The open channel along the c-axis is indicated hy the dashed Ifnes.

Fig. 10. Log $f_{\text {Co }}$ vs reciprocal absolute temperature for cobalt diffusion in Nin. From Chen and Peterson [23].

Fig. 11. Temperature dependence of (a) $\mathrm{D}_{\mathrm{Co}} / \mathrm{D}_{\mathrm{Ni}}(0)$ and (b) $\mathrm{w}_{2} / \mathrm{w}_{\mathrm{o}}(\mathrm{A})$ as calculated from measured values of $f_{\mathrm{Co}}$. Experimental data from the simultaneous diffusion of ${ }^{60} \mathrm{Co}$ and ${ }^{57} \mathrm{Ni}(\dot{\varphi})$ are also shown. From Chen and Peterson [23]. 
$\because \bigoplus$

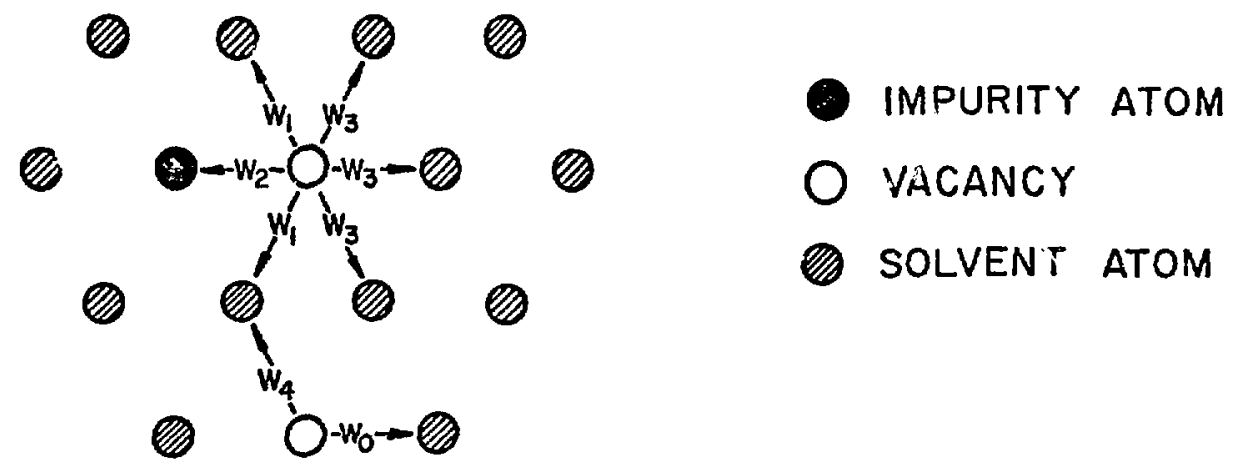

Fig. 1. Vacancy jumps near an impurity in an fcc crystal. 


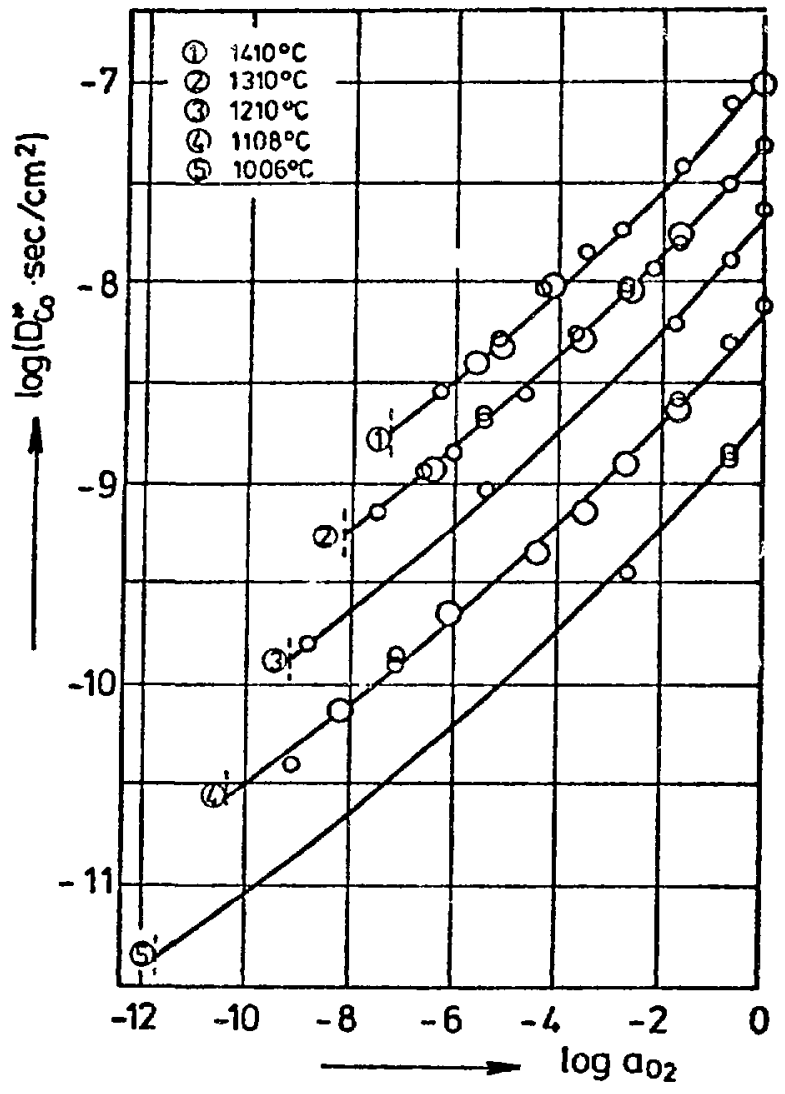

Fig. 2. Cation self-diffuston as a function of the oxygen partial pressure in $\mathrm{Co}_{1-\delta^{\circ}}$ in the temperature range $1000-1400^{\circ} \mathrm{C}$. From Dieckmann [13]. 


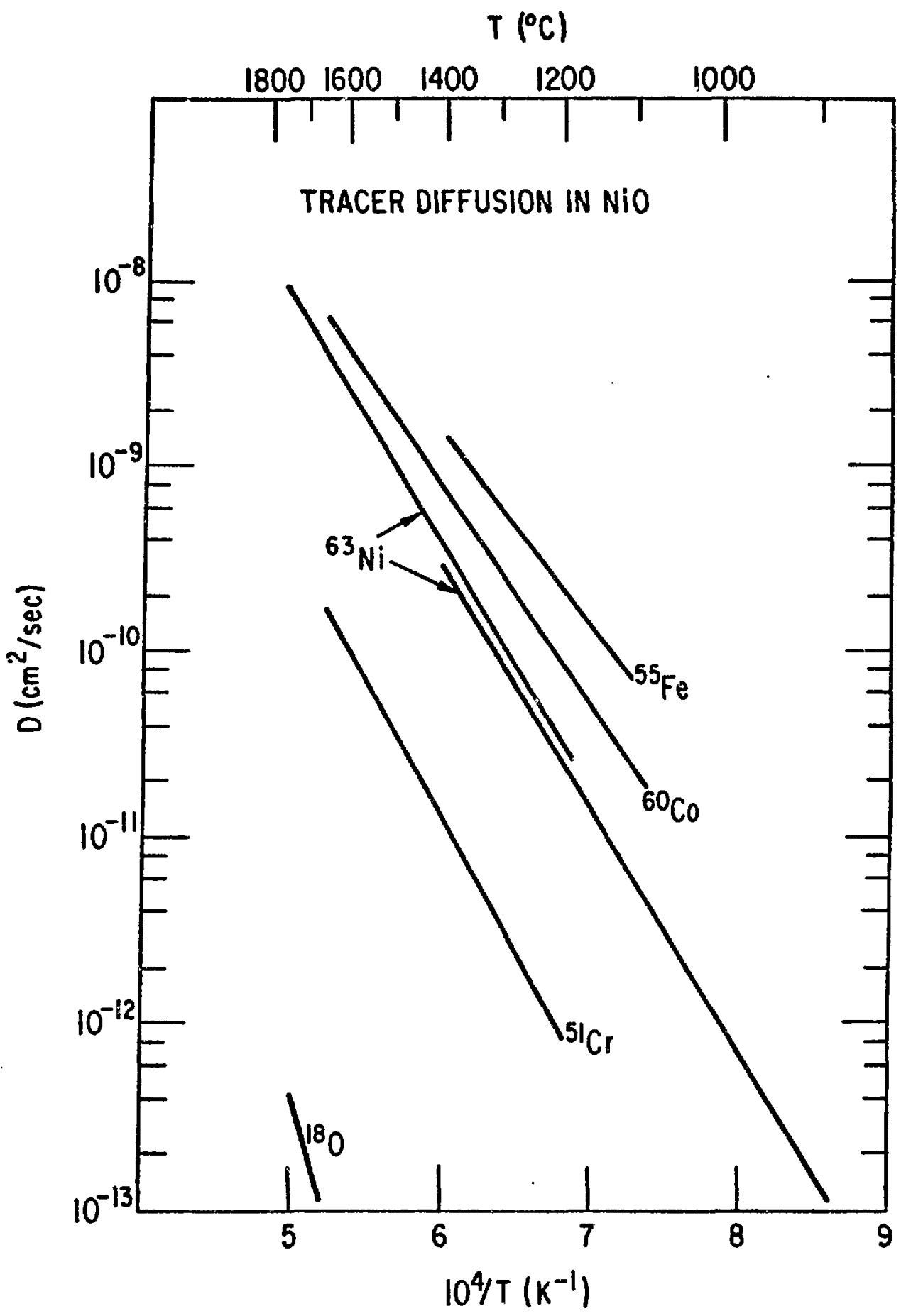

$\mathrm{Fig}$. 3. Tracer diffusion in $\mathrm{N} 1 \mathrm{O}_{5}$ at $\mathrm{PO}_{2}=0.21$ atm. The data are from the following references: $55 \mathrm{Fe}--\mathrm{C}$. ow [12]; $60 \mathrm{Co}-\mathrm{Chen}$ and Peterson $[22,23]$; high-temperature ${ }^{63} \mathrm{Ni}-$ Volpe ani Reddy [18] and Chen and

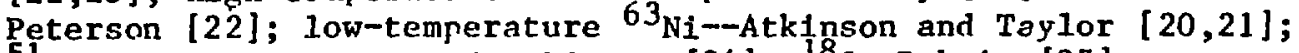
$51 \mathrm{Cr}-$ Chen, Peterson and Robinson [24]; ${ }^{18} \mathrm{O}$--Dubols [25]. 


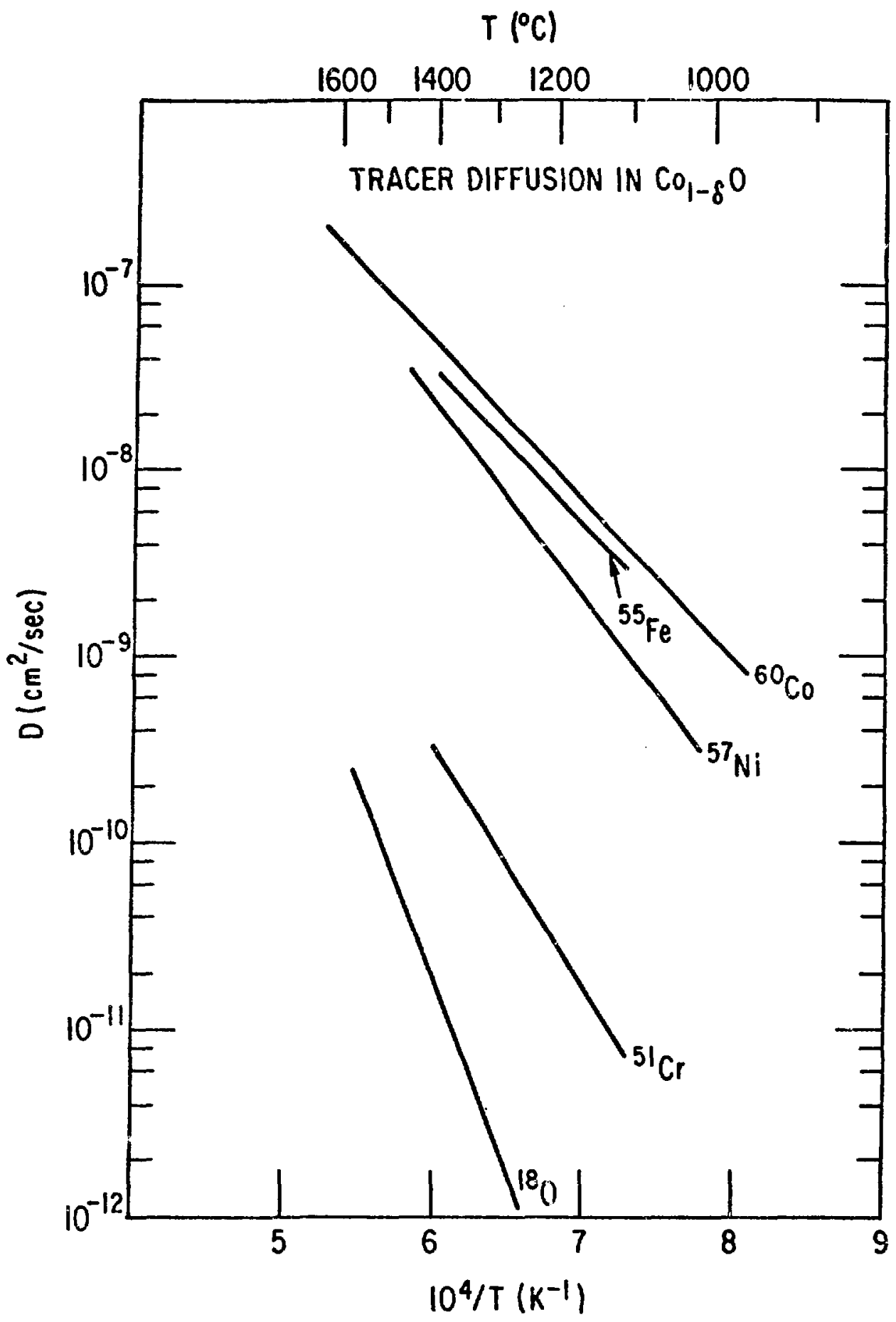

Fig. 4. Tracer diffusion in $\mathrm{Co}_{1-\delta^{\mathrm{O}}}$ at $\mathrm{PO}_{2}=0.21$ atm. The data are from the following references: ${ }^{60} \mathrm{Co}-$-Carter and Richardson [5], Chen, Peterson and Reeves [11], Chen and Peterson [22], and Dieckmann [13]; ${ }^{55} \mathrm{Fe}-$-Crow $[12] ;{ }^{57} \mathrm{Ni}-$-Chen and Peterson [22]; ${ }^{51} \mathrm{Cr}-$-Chen $[30] ;{ }^{18} 0--C h e n$ and Jackson $[15]$. 


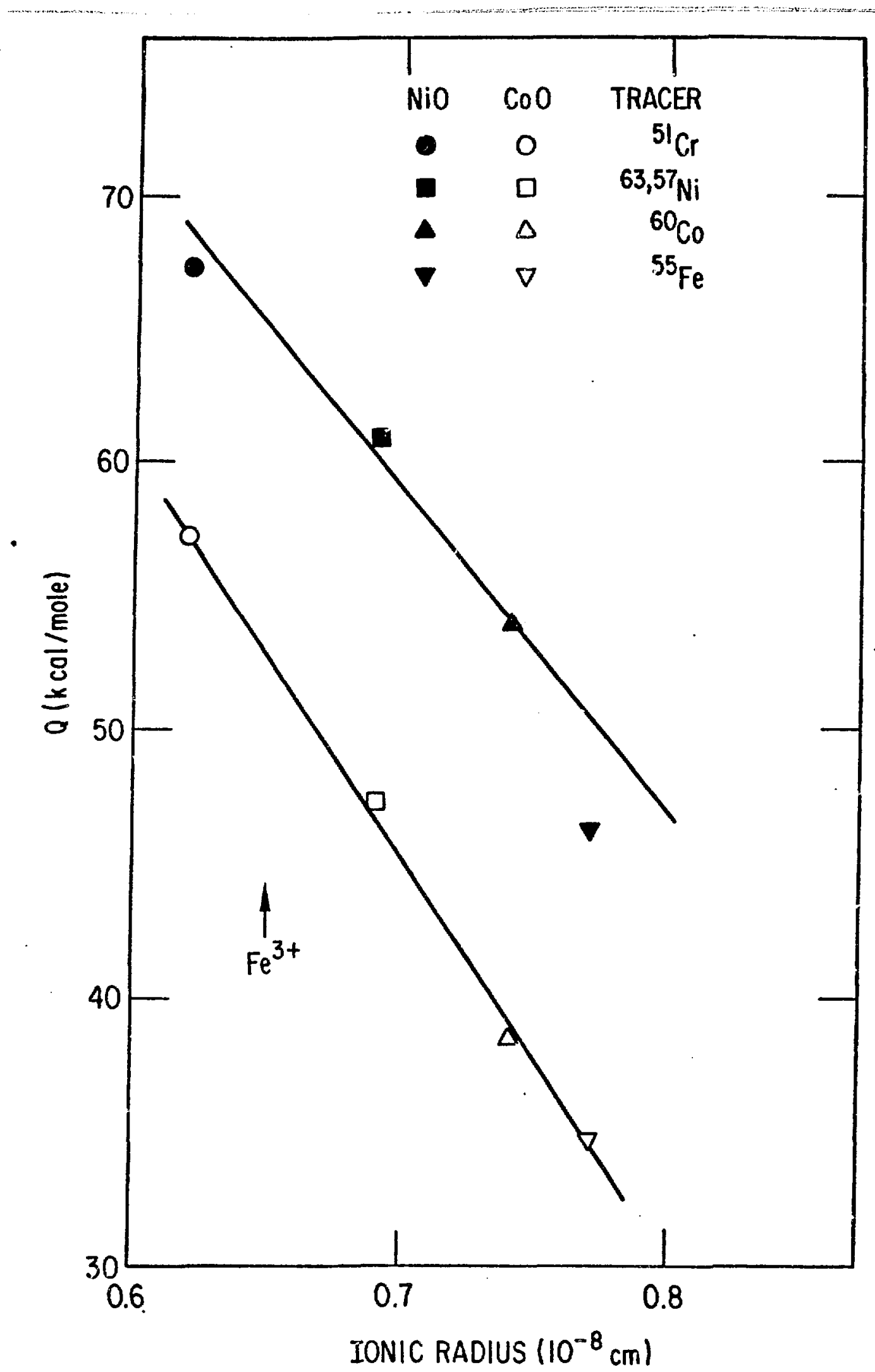

Fig. 5. Activation energy for tracer diffusion in $\mathrm{NIO}$ and $\mathrm{Co}_{1-\delta^{0}} \mathrm{vs}$ Ionic radius of the tracer ion. 
MORMally OCCUPIED tE TRAHEDRAL SITES (DIAMONU SUBLATTICE)

O MORMALEY UNOCCUPIED TETRAHEDRAL SITES

- NORMALLY UNOCCUPIED OCTAHEDRAL SITES

(ASSUMEO INTERSTITIAL SITES IN MECHANISM 2)

- TETRAHEORAL VaCANCY (MECHANISM I)

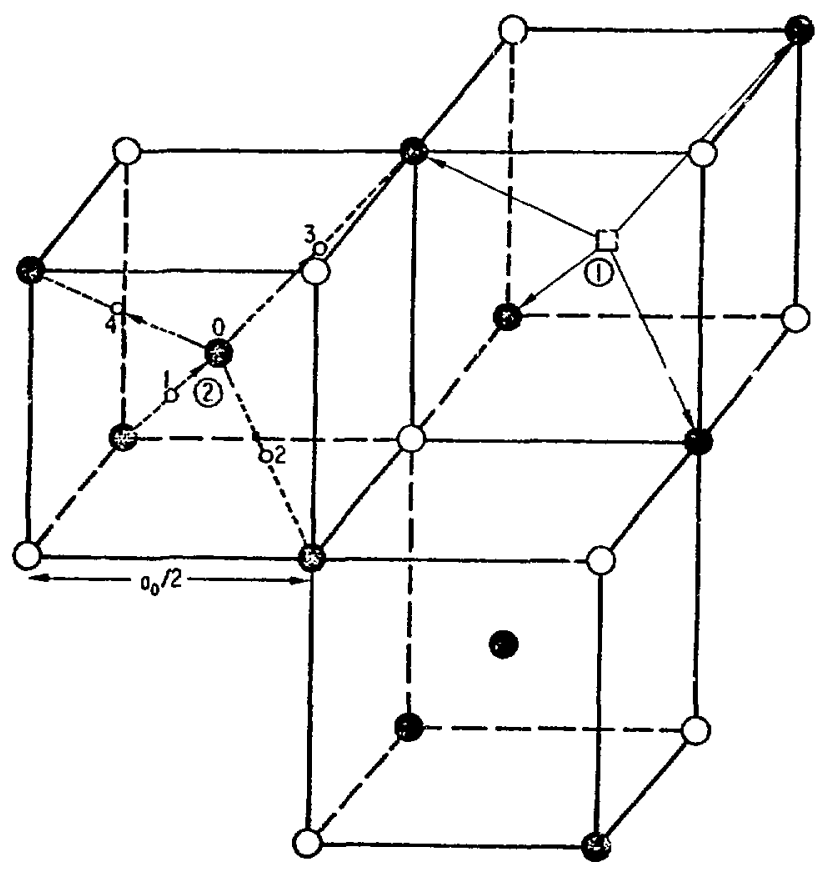

Fig. 7. Vacancy and interstitialcy jumps mainly involving cation tetrahedral sites in the $\mathrm{Fe}_{3} \mathrm{O}_{4}$ lattice. The oxygen sites are omitted for clarity. From Peterson et al. [43]. 




Fig. 8. Tracer diffusion in $\mathrm{Fe}_{3} \mathrm{O}_{4}$ as a function of the oxygen partial pressure at $1200-1210^{\circ} \mathrm{C}$. The data are from the following referencus; $59 \mathrm{Fe}-$ Dieckmann and Schmalzried $[42] ;{ }^{60} \mathrm{Co}$ and ${ }^{51} \mathrm{Cr}-$ Dieckmann, Mason, Hodge, and Schnalzried [44]. 


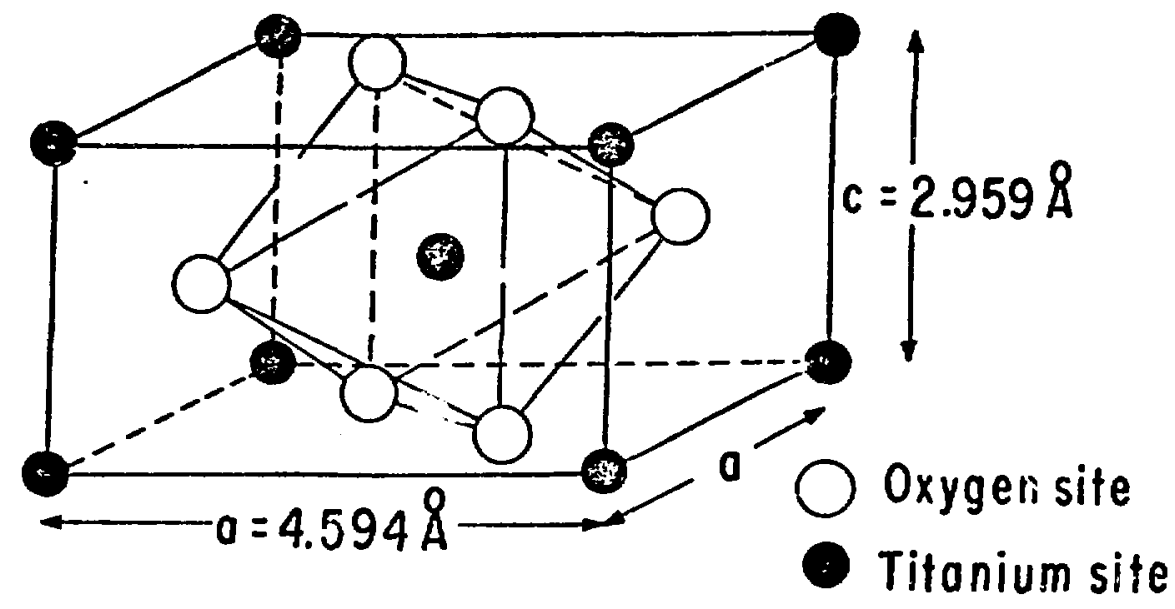

(a)
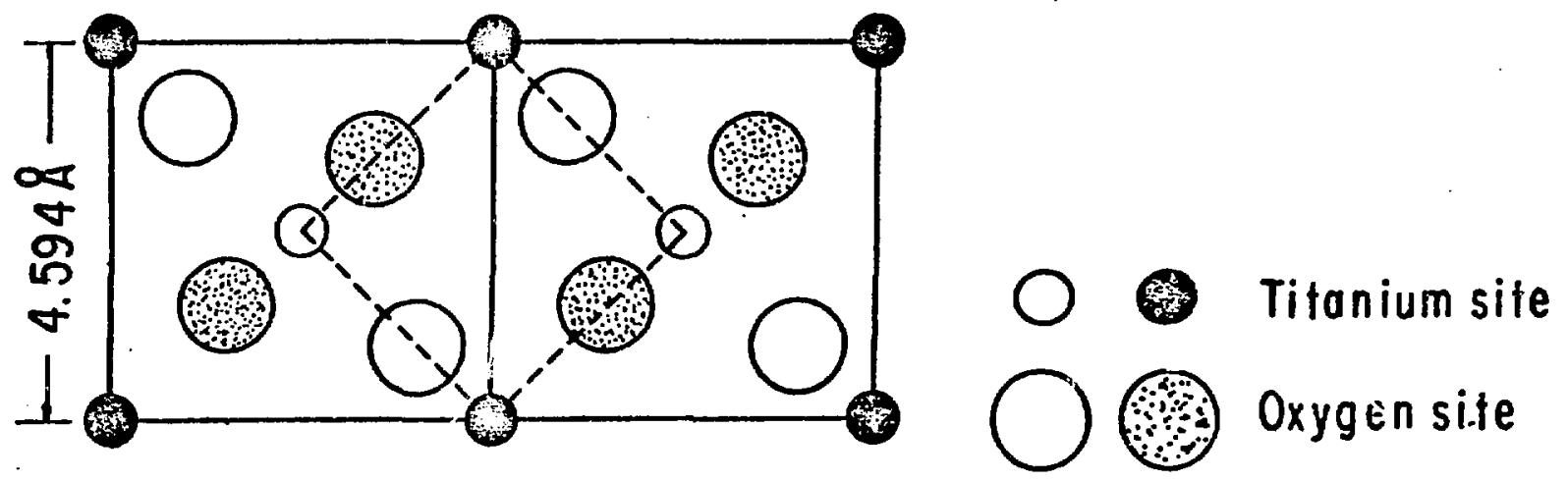

(b)

FIg. 9. (a) A unft cell of the rutile $\left(\mathrm{THO}_{2}\right)$ etructure. (b) An end view of the atomic arrangement for the [001] axial direction. The open channel along the c-axis is indicated by the dashed lines. 


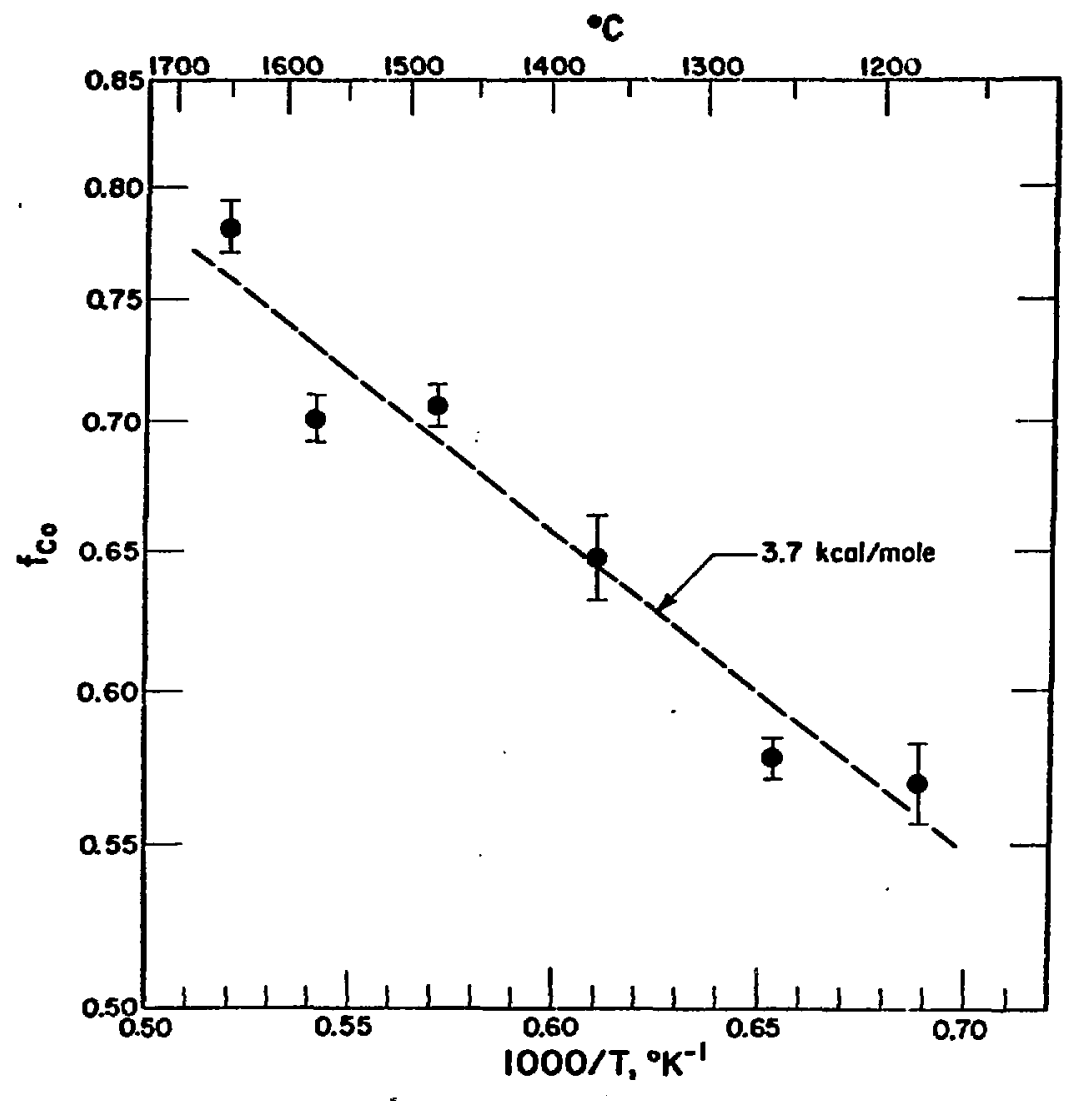

Fig. 10. Log $f_{C o}$ vs recjprocal absolute temperature for cobalt diffusion in NiO. From Chen and Peterson [23]. 


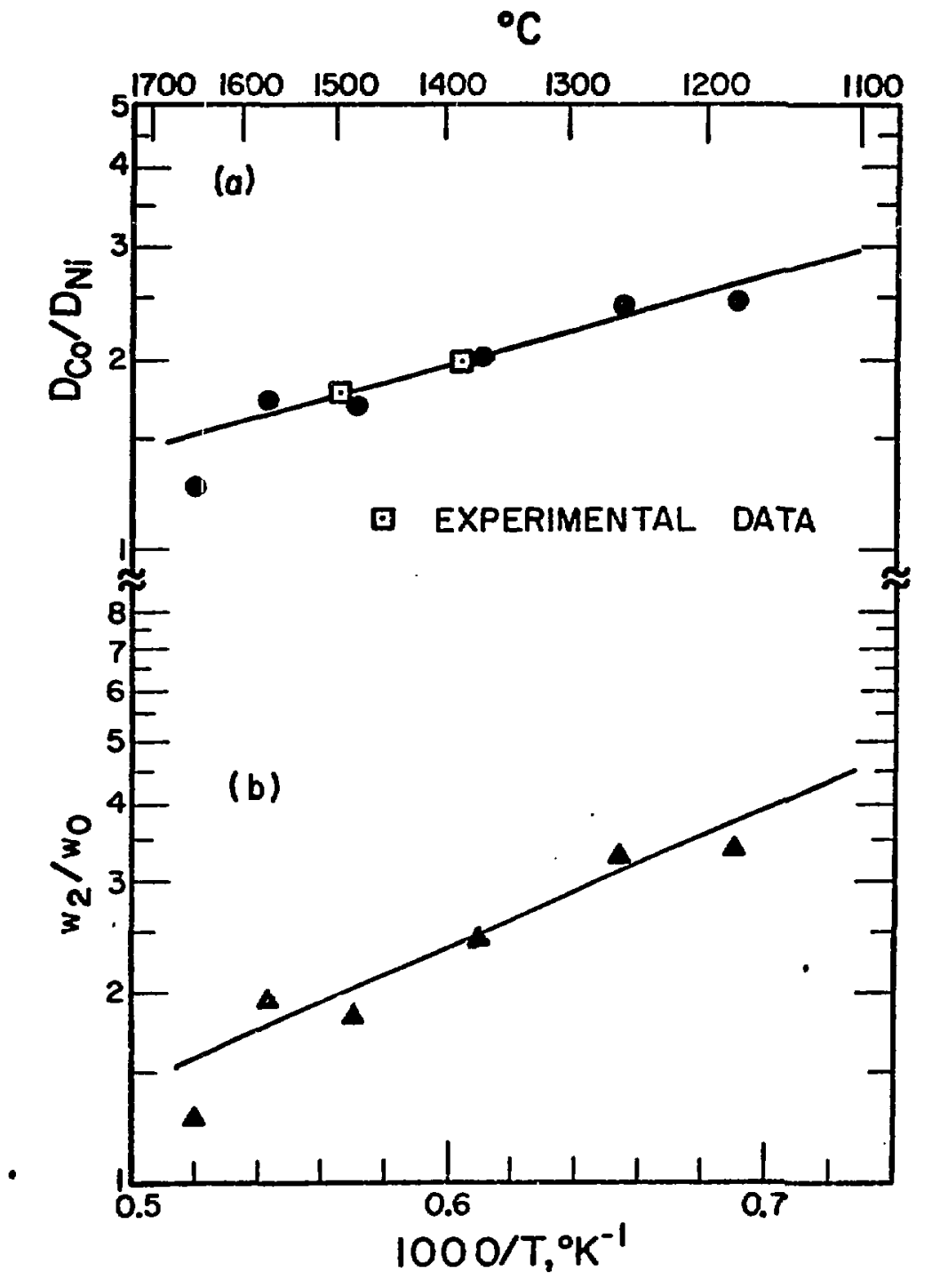

Fig. 11. Temperature dependence of (a) $\mathrm{D}_{\mathrm{Co}} / \mathrm{D}_{\mathrm{NI}}$ (6) and (b) $\mathrm{w}_{2} / \mathrm{w}_{\mathrm{O}}$ ( A ) as calculated from measured values of $\mathrm{f}_{\mathrm{C}}$ Experimental data from the sinultaneous diffusion of $60^{\circ}$ and $57_{\mathrm{Ni}}(\square)$ are also shown. From Chen and Peterson [23]. 